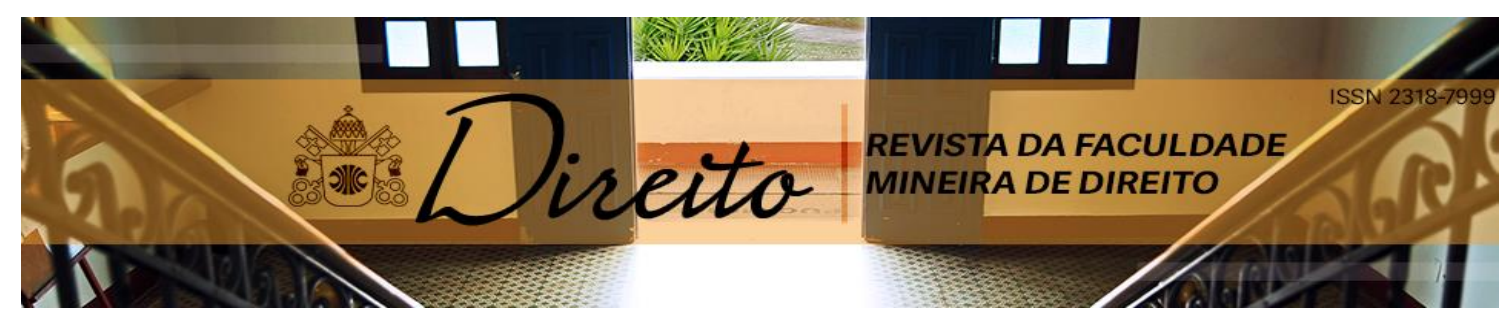

\title{
REALIZAÇÃO DEMOCRÁTICA DOS DIREITOS DIFUSOS: APÓS A GERAÇÃO DOS DIREITOS DESUMANOS E O FENÔMENO FREE RINDING
}

\author{
DEMOCRATIC REALIZATION OF DIFFUSE RIGHTS: AFTER GENERATION OF \\ INHUMAN RIGHTS AND THE PHENOMENON FREE RINDING
}

Norton Maldonado Dias ${ }^{1}$

Edinilson Donisete Machado²

\begin{abstract}
Resumo
No contexto da terceira dimensão de direitos fundamentais surgiram os aclamados direitos difusos, em suma, o modo de proteção jurídica passou a declinar por prerrogativas caracterizadas por não especificarem sujeitos determinados, dentre os quais, o patrimônio histórico, meio ambiente e outros. Ocorre que esta mudança na tutela jurídica de proteção foi compreendida com significativas respostas estatais à violência, guerras e atrocidades que abalaram a humanidade na metade do século XX, buscando na política das proteções jurídicas conteúdos que não beneficiavam especificamente categorias determinadas, incluindo referenciais burgueses verificáveis em gerações de direitos anteriores. $O$ trabalho busca transcrever, através da metodologia dedutiva, uma perspectiva subjetiva para terceira geração de direitos, enfatizando o enfrentamento do fenômeno free rinding.
\end{abstract}

Palavras Chaves: Direitos Difusos. Direitos de Terceira Geração. Free Rinding.

Abstract
In the context of the third dimension of fundamental rights appeared the acclaimed diffuse rights , in short, the legal protection so began to decline prerogatives characterized by not specifying certain subjects, among which, the historical heritage, environment and others. It happens that this change in legal guardianship protection was understood to significant state responses to violence, wars and atrocities that shook humanity in the mid-twentieth century, seeking the policy of legal protections content not specifically benefited certain categories, including verifiable bourgeois reference in previous generations of rights. The search work transcribe, through the deductive methodology, a subjective perspective for third rights generation, emphasizing the confrontation of Free Rinding phenomenon.

Key words: Diffuse Rights. Rights of Third Generation. Free Rinding.

Artigo recebido em 04 de Outubro de 2016 e aprovado em 10 de abril de 2017.

1 Mestre em Direito e professor pelo Centro Universitário Eurípides de Soares da Rocha, São Paulo, São Paulo, Brasil.

2 Doutor e professor pela Pontifícia Universidade Católica de São Paulo, São Paulo, São Paulo, Brasil.

RFMD, Belo Horizonte, v. 20, n. 39, p. 111-133, out./abr. 2017 - INSS 2318-7999 


\section{INTRODUÇÃO}

Por meio do método dedutivo e verificando o pensamento de Karel Vasak acerca das acepções que ficaram conhecidas como "gerações" ou "dimensões" de direitos, vale destacar um dos trabalhos que mais bem divulgaram 0 pensamento das "gerações" ou "dimensões" de direitos, correspondente a obra intitulada "A Era dos Direitos" de autoria de Norberto Bobbio, onde o próprio autor assume uma pontual divergência em relação ao filósofo alemão Karl Marx em um trabalho denominado "Sobre a Questão Judaica".

Ocorre que o trabalho de Karl Marx, intitulado "Sobre a Questão Judaica", destaca que um dos documentos de maior relevância pertencente a primeira dimensão dos direitos, em suma, a declaração não referenciava o homem universal, mas sim o homem burguês, verificando uma análise em que Karl Marx se volta aos verdadeiros beneficiários e favorecidos com as proteções no respectivo contexto político e histórico em que este primeiro momento de proteção favoreceu, restringindo-se a uma análise estritamente subjetiva acerca "de quem?" e "sobre quem?" estava sendo considerado nas respectivas proteções.

A perspectiva subjetiva da primeira dimensão de direitos fundamentais é orientada no sentido de concluir que direitos abstratamente universais começam a ser tutelados na medida ou tendo em vista categorias subjetivas que, de fato, seriam os principais beneficiários das respectivas proteções, no caso da primeira dimensão de direitos em que há escopo precipuamente liberal considerou principalmente a burguesia da época, inclusive categoria vencedora na Revolução de 1789.

Ocorre que a análise subjetiva de Karl Marx acaba sendo retomada neste trabalho como uma forma de desenvolver uma perspectiva que por muito tempo foi afastada em razão do aspecto da universalidade abstrata desses direitos que Bobbio invocou com o propósito de resistir ao pensamento e análise subjetiva feita por Karl Marx em um dos mais relevantes documentos pertencentes à primeira dimensão de direitos.

O objetivo deste trabalho não está reduzido a tão somente retomar a perspectiva subjetiva de Karl Marx para as dimensões de direitos fundamentais, 
mas sim estender esta perspectiva subjetiva que investigam beneficiários e favorecidos no decorrer das dimensões de direitos fundamentais, mas também desenvolver esta perspectiva subjetiva para a aclamada terceira dimensão de direitos, especificamente o surgimentos dos compreendidos direitos difusos que pacificamente foram determinados no terceiro momento de proteção de direitos fundamentais que ficou conhecido como terceira dimensão de direitos.

A hipótese desta proposta se pauta em relacionar os problemas de legitimidade em materializar e representar direitos difusos determinados na terceira dimensão de direitos com uma nova proposta de proteção e positivação de prerrogativas que tiveram como intento responder as crises humanitárias provocadas pela violência e dos sangrentos episódios da guerra e do Holocausto que assolaram a humanidade até a metade do século $X X$.

Trata-se não só de rever o pensamento geracional a luz de um novo ponto de vista, mas aplicar está análise subjetiva que Karl Marx realizou somente para um dos documentos inseridos em um primeiro momento de proteção, mas estendê-la também para a terceira dimensão de direitos.

\section{DESENVOLVIMENTO}

\section{Revendo as Gerações (Dimensões) de Direitos na Perspectiva Subjetiva de Karl Marx}

O pensamento das gerações dos direitos fundamentais na atualidade consiste em um pensamento bastante divulgado e repercutido dentro da temática dos direitos fundamentais.

Elaborado por um autor tchecoslovaco naturalizado na França chamado Karel Vasak, a proposta defende a ideia de determinação dos direitos fundamentais a partir de uma ordem de proteção no histórico do constitucionalismo, orientanda por uma primeira geração de direitos, onde foram previstos os direitos civis e políticos; uma segunda geração de direitos onde foram previstos dos direitos sociais e econômicos e uma terceira geração de direitos que na proposta genuína encerra os momentos de proteção e que se relacionam com os direitos relativos à fraternidade, dentre os quais, os direitos coletivos. 
Logicamente que doutrinas têm afirmado outras gerações de direitos, bem como uma mudança terminológica nas fases de proteção que, originariamente, foram chamados de "gerações", mas que propostas constitucionalistas mais recentes optaram de forma acertada pela nomenclatura de "dimensões" de direitos.

A evolução terminológica que mudou as intitulações de "gerações" para "dimensões" de direitos ocorreram por razões de que a expressão "gerações" trazia consigo uma ideia sucessões, ou seja, de um momento ou contexto que sucedia, ou melhor, encerrava-se em detrimento de outro ulterior e, de fato, não se trata de sucessão, encerramento ou substituição de direitos em razão de fase vindoura, mas sim de um cúmulo de direitos no decorrer das diferentes dimensões ou fases de previsão jurídica.

No caso do objeto desta proposta, vale relevar a terceira dimensão de direitos como forma de destacar uma mudança nas prerrogativas que foram positivadas nesse contexto, trazendo questionamentos acerca de, por exemplo, direito da paz compreendido como um direito protegido pertencente à terceira dimensão:

[...] direito a paz foi classificado por Karel Vasak como de $3^{\underline{a}}$ dimensão. Contudo Paulo Bonavides entende que o direito à paz deva ser tratado em dimensão autônoma, chegando a afirmar que a paz é axioma da democracia participativa, ou, ainda, supremo direito da humanidade. ${ }^{1}$

Atenta-se para o critério em que se pautou a teoria das gerações (dimensões) de direitos na determinação ou surgimento de prerrogativas compreendidas como fundamentais, sendo, justamente, o critério positivista de condicionar direitos a uma cronologia de formalização e positivação de conteúdos.

Tal critério formalista e, sobretudo, positivista tem trazido vários vícios e problemas, dentre os quais, o exemplo da vertente internacionalista que conferiu a ordem de previsão de direitos relativos a pessoa humana ocorrido nos Tratados e Convenções Internacionais, concluindo que no âmbito dos Tratados e Convenções Internacionais, os direitos atinentes a pessoa humana não começaram com os direitos civis e políticos como pretendeu Karel Vasak com a

\footnotetext{
${ }^{1}$ BONAVIDES, Paulo. Curso de Direito Constitucional. 7. ed. São Paulo: Malheiros, 1998, p. 593.
} 
proposta das gerações de direitos, mas sim com os direitos sociais, haja vista que o primeiro documento internacional que protegeu direitos atinentes a pessoa humana corresponde

à Convenção da OIT - Organização Internacional do Trabalho de 1919.

Nesse sentido têm-se os seguintes autores que reforçam o descompasso existente entre a cronologia de positivação de direitos verificável no histórico do constitucionalismo em detrimento aos documentos de essência internacional, tais como Flávia Piovesan, Cançado Trindade, Jairo Schäfer (talvez seu maior crítico), Carlos Weis e o próprio Valério Mazzuoli que é bastante claro quando diz:

[...] a consagração nas Constituições dos direitos sociais foi, em geral, posterior à dos direitos civis e políticos, ao passo que no plano internacional o surgimento da Organização Internacional do Trabalho, em 1919, propiciou a elaboração de diversas convenções regulamentando os direitos sociais dos trabalhadores, antes mesmo da internacionalização dos direitos civis e políticos no plano externo. ${ }^{2}$

descompasso existente decorre, justamente, do critério em que se pautou a proposta teórica de Karel Vasak, baseado, precisamente, na determinação de direitos fundamentais a partir de quando foram protegidos e positivados.

Portanto, pode-se apontar uma crise das gerações (dimensões) de direitos em razão do critério de previsão que se utilizou, relevando o levantamento de uma análise dos direitos que foram sendo protegidos (critério do conteúdo) e dos sujeitos que se beneficiaram no decorrer das seguintes proteções (critério dos sujeitos) no decorrer das diferentes gerações.

A doutrina e tão somente a vertente internacionalista relata a crise da proposta teórica das gerações (dimensões) de direitos, de modo que muitos constitucionalistas e juristas de significativo renome continuam reafirmando a acepção teórica das gerações (dimensões) de direitos, de modo que vale a proposta não só restrita a relatar a crítica dos autores internacionais, dentre os

\footnotetext{
${ }^{2}$ MAZZUOLI, Valério. O. Curso de direito internacional público. 7. ed. São Paulo: Revistas dos Tribunais, 2013, p. 858.
} 
quais, Cançado Trindade, Flávia Piovesan, Carlos Weis, Jairo Schafer e Valério Mazzuoli, mas acrescer a temática de crise das gerações (dimensões) de direitos por uma perspectiva ainda não abordada por nenhum autor, em suma, do ponto de vista da subjetividade e da efetividade (afastando a universalidade e a abstração positivista), correspondente a uma contribuição que demonstre que no plano da efetividade e da cronologia histórica de proteção, os direitos fundamentais compreendidos como universais só foram protegidos em momentos e contextos históricos diversos para serem efetivos somente para categorias específicas de sujeitos, reduzindo a universalidade de direitos a uma teorização que não transcendeu o plano da respectiva previsão jurídica no decorrer das diferentes gerações (dimensões) de direitos.

Esta afirmativa começa ser desenvolvida a partir de uma pontual celeuma assumida por Norberto Bobbio na obra "Era dos Direitos", onde o jurista diverge do filósofo alemão Karl Marx quando diz que a declaração como um dos mais significativos documentos pertencentes à primeira geração (dimensão) de direitos não referenciava o homem universal, mas sim o burguês:

[...] De nenhum modo se tratava do homem abstrato, universal! O homem de que falava a declaração era, na verdade, o burguês; os direitos tutelados pela Declaração eram direitos do burguês, do homem (explicava Marx) egoísta, do homem separado dos outros homens e da comunidade, do homem enquanto 'mônada isolada e fechada em si mesma' (...) A acusação feita por Marx à Declaração era a de ser inspirada numa concepção individualista da sociedade. A acusação era justíssima. ${ }^{3}$

No próprio trabalho, Norberto Bobbio reconhece que foram protegidos direitos universais não por uma unanimidade de todos, mas de um interessado naquele respectivo contexto histórico e políticos das aclamadas primeiras gerações (dimensões) de direitos, como forma de buscar a própria emancipação contextualizada contrariamente a resistência aristocrática daquela época:

A crítica oposta - segundo a qual a Declaração, em vez de ser demasiadamente abstrata, era tão concreta e historicamente determinada que, na verdade, não era defesa do homem em geral, que teria existido sem que o autor das Noites de São Petersburgo o soubesse, mas o burguês, que existia em carne e osso e lutava pela própria

\footnotetext{
${ }^{3}$ BOBBIO, Norberto. A Era dos Direitos. Elsevier; Rio de Janeiro; 2004; p. 46.
} 
emancipação de classe contra a aristocracia, sem se preocupar muito com os direitos do que seria o chamado Quarto Estado - foi feita pelo jovem Marx no artigo sobre a "questão judaica", suficientemente conhecido para que não seja preciso nos ocuparmos de novo dele, e repetida depois, ritualmente, por diversas gerações marxistas. ${ }^{4}$

Percebe-se que direitos teorizados como universais enquanto referenciavam a todos os seres humanos, porém somente protegidos naquele específico momento para emancipação e efetivação de alguns.

A continuidade do texto trabalhado por Norberto Bobbio nesta obra intitulada "A Era dos Direitos" irá retomar a universalidade dos direitos e se afastar da análise subjetiva feita por Karl Marx, de modo que a reafirmação da universalidade acaba afastando especificações subjetivas, justamente, por referenciar a natureza humana de modo geral e, consequentemente, o ideário das gerações (dimensões) de direitos prosseguirá se desenvolvimento na abordagem da obra que mais divulgou o pensamento de Karel Vasak dentro da perspectiva da universalidade abstrata e se atentando à perspectiva do conteúdo e não dos sujeitos.

A proposta de retomar a análise subjetiva de Karl Marx para inserir na temática de crise das gerações de direitos, terá como propósito integralizar a proposta, não só dentro da linha de autores internacionalistas, mas também na perspectiva dos beneficiados e favorecidos no curso histórico da diferentes gerações (dimensões) de direitos.

Vale lembrar que a corrente que defendeu uma significativa crise das gerações (dimensões) de direitos foi, justamente, o pensamento que apontou desvios no histórico de proteção de direitos que a luz dos Tratados e Convenções Internacionais que começaram o seu respectivo âmbito de proteção dos direitos sociais e não dos direitos civis e políticos por razões do critério que foi adotado na determinação dos direitos fundamentais, no caso da proposta de Karel Vasak, baseado em certa ordem cronológica histórica de proteção.

Ocorre que direitos compreendidos como fundamentais não foram determinados ou surgiram somente a partir do momento em que foram protegidos no histórico do constitucionalismo, mas de diversos outros fatores de natureza histórica, antropológica, sociológica e outras influências, admitindo que

\footnotetext{
${ }^{4}$ BOBBIO, Norberto. A Era dos Direitos, p. 46.
} 
o fator da cronologia de proteção jurídica a tão somente uma das influências a serem consideradas, de modo a não ter aptidão sozinha e isoladamente à única fonte de determinação de direitos fundamentais.

Sendo válida a verificação de quem ou quais foram os sujeitos, de fato, beneficiados com uma determinada proteção jurídica para fins de esclarecimento do interesse político em questão, admitindo a exclusão quando uma determinada gama de prerrogativas teorizadas como de todos, mas que na proteção jurídica confirma uma contextualização política que tem em vista categorias beneficiadas e excludentes e tal afirmativa pode ser verificada não só na Declaração dos Direitos do Homem e do Cidadão, mas em outro famoso e significativo documento pertencente à primeira geração (dimensão) de direitos:

O direito à liberdade e à busca da felicidade que constava na Declaração de independência dos EUA não valia para todas as pessoas. A escravidão negra, por exemplo, foi plenamente mantida nos Estados Unidos até a Guerra da Secessão (1861-1865). Os autores da independência dos Estados Unidos não se preocuparam com mais de um milhão de negros que sofriam tortura, exploração e humilhação do trabalho escravo. Aliás o próprio Thomas Jefferson foi um dos grandes proprietários de escravos de seu tempo, embora fosse, teoricamente, antiescravista e abolicionista (... ${ }^{5}$.

A questão histórica dos índios americanos que estavam submetidos a sujeições bastante similares ainda quando no âmbito das proteções jurídicas havia significativos avanços nas expressões liberdade e felicidade:

[...] Os índios americanos também não tiveram o mesmo direito à liberdade e à felicidade garantidas aos proprietários burgueses. Durante todo o período colonial e depois da independência, receberam dos brancos o massacre de suas tribos, a destruição de sua cultura e a expulsão de suas terras. Até mesmo as mulheres americanas não desfrutavam os mesmos direitos civis reservados aos homens. Naquela época, a mulher era considerado um ser inferior e, por isso, permaneceu subordinada ao poder absoluto do homem. Quem, então, exercia plenamente os direitos de cidadão, assegurados na constituição americana de 1787? Em linhas gerais, a plena cidadania foi exercida pela poderosa burguesia industrial e

\footnotetext{
${ }^{5}$ COUTRIN, Gilberto. História \& reflexão Consolidação do Capitalismo e Brasil Império. vol. 3;
} ed. Saraiva; 8ª edição; 1999; São Paulo, p. 44. 
comercial do Centro-Norte e pelos donos de fazenda do Sul $[\ldots]^{6}$.

Para além da obra intitulada "A Era dos Direitos" que faz referencia a esta celeuma entre Norberto Bobbio e Karl Marx acerca da Declaração francesa, vale aprofundamento deste outro relevante documento inserido na primeira geração (dimensão) de direitos, correspondente a Declaração de Independência dos Estados Unidos que foi preparada por um comitê de cinco membros, presidido por Thomas Jefferson (1743-1826), pois estes documentos de inspirações, também, iluministas, defendendo a liberdade individual do cidadão e com significativas críticas a tirania dos governantes ${ }^{7}$.

O sociólogo Lucien Goldman é um dos vários autores que também retrata a desmistificação dos valores universais referenciados no "Lema de Mariana" utilizado na Revolução Francesa de 1789 (Liberdade, Igualdade e Fraternidade):

Igualdade: no ato de comércio, isto é, no ato de compra e venda, todas as eventuais desigualdades sociais entre compradores e vendedores não tinham importância. Na compra e venda, o que efetivamente importava era a igualdade jurídica dos participantes do ato comercial. Por isso, os iluministas defendiam que todos deveriam ser iguais perante a lei. Ninguém teria, então, privilégios de nascença, comos os que a nobreza apresentava no Antigo Regime. Entretanto, a igualdade jurídica não significava igualdade econômica, a maioria dos iluministas acreditavam que a desigualdade correspondia a ordem natural das coisas. ${ }^{8}$.

A proposta de Karel Vasak, portanto, baseou-se em um critério formal e positivista que vislumbra a determinação de direitos compreendidos como fundamentais a partir dos momentos de previsão jurídica no histórico do constitucionalismo, tratando-se de um critério formalista e variável que não consegue se manter quando se altera a natureza do documentos de proteção, tal como, Tratados e Convenções Internacionais, haja vista o descompasso já abordado que admite que a Convenção da OIT (Organização Internacional do

\footnotetext{
${ }^{6}$ COUTRIN, Gilberto. História \& reflexão Consolidação do Capitalismo e Brasil Império, p. 44.

${ }^{7}$ COUTRIN, Gilberto. História \& reflexão Consolidação do Capitalismo e Brasil Império, p. 45.

${ }^{8}$ GOLDMAN apud COUTRIN, História \& reflexão Consolidação do Capitalismo e Brasil Império, p. 20.
} 
Trabalho) de 1919 protegeu primeiro os direitos atinentes ao trabalho e não os direitos civis e políticos na proposta da gerações (dimensões) de direitos elaboradas pelo jurista tcheco Karel Vasak.

$\mathrm{Na}$ obra "A Era dos Direitos" de Norberto Bobbio que também foi um propulsor das ideias das gerações (dimensões) de direitos de Vasak, encontrase a já abordada divergência pontual em face ao trabalho de Karl Marx intitulado "Sobre a Questão Judaica", onde o filósofo alemão inaugura a perspectiva subjetiva apontando o favorecido com a declaração que referenciou o burguês como beneficiário da Revolução de 1789 que encerrou a estrutura aristocrática daquilo que ficou compreendido como antigo regime: "(...) De nenhum modo se tratava do homem abstrato, universal! O homem de que falava a declaração era, na verdade, o burguês; os direitos tutelados pela Declaração eram direitos do burguês" 9 .

Quando Norberto Bobbio reafirma a universalidade, alinha-se 0 desenvolvimento teórico e doutrinário em uma espécie de distanciamento da ideia de que direitos universais e de todos enquanto seres humanos não conseguem superar ou transcender o âmbito formal de suas previsões e textualizações, reduzindo a efetividade de alguns em detrimentos dos demais a depender dos agentes políticos de um dado contexto histórico.

As análises de documentos pertencentes a primeira geração (dimensão) acabaram sendo as únicas que tiveram seus conclusivos sobre quem de fato viram seus direitos serem efetivados e a ideia da proposta de retomar a perspectiva subjetiva e da efetividade (critério dos sujeitos) em detrimento a perspectiva formal e positivista (critério dos conteúdos), porém não só para as primeiras gerações (dimensões) de direitos, mas também ampliando tal análise subjetiva para a segunda e terceira geração (dimensão) de direitos dentro da proposta teórica genuína e afastada por Norberto Bobbio.

A proposta de Karel Vasak de invocar o valor liberdade do lema revolucionário setecentista para um primeiro momento do constitucionalismo alcunhado como geração ou dimensão de direitos teve um significativo e pretenso interesse econômico e mercantilista:

Liberdade pessoal e social: a atividade comercial burguesa só poderia desenvolver-se numa economia de mercado, ou

${ }_{9}^{9}$ BOBBIO, Norberto. A Era dos Direitos, p.46 
seja, era preciso que existisse o jogo livre da oferta e da procura. Por isso, a burguesia se opôs a escravidão humana e passou a defender uma sociedade 'livre'. Afinal, sem trabalhadores livres, que recebessem salário não poderia haver mercado comercial. ${ }^{10}$

A liberdade, na verdade, era um valor primordial para efetivar as relações de troca e o respectivo nivelamento de todos à condição de sujeito de direitos garantiria a igualdade nessas relações como forma de equiparação elemento volitivo indispensável nas relações contratualistas.

Não há aqui propósitos de reafirmar linhas marxistas, mas não se pode incorrer na leviandade de negar a efetividade de interesses, justamente, daqueles a quem mais interessou o êxito no contexto político da Revolução de 1789, incluindo a proteção do valor liberdade como uma abrangência que não só referencia a todos enquanto seres humanos, mas que sendo de todos enquanto seres humanos e por tempo ilimitado, vale a investigativa e suspeição de uma proteção jurídica pontualmente ocorrida no exato contexto histórico e político onde os mais favorecidos foram à classe que considerada vitoriosa no episódio revolucionário francês de 1789.

Foi preciso elevar a condição de objeto de direito (exemplo do escravo) dos seres humanos para uma condição superior consistente na condição de sujeitos de direitos, de modo a nivelar suas vontades a uma condição igual para as respectivas relações contratuais de troca, podendo afirmar uma significativa criação jurídica, positivista e abstrata, correspondente à figura do sujeito de direitos ou da subjetividade jurídica.

O próprio autor Hans Kelsen com a autoridade maior concernente ao positivismo jurídico chegou a reconhecer em sua obra intitulada "Teoria Pura do Direito" os reais propósitos e a ideologia por detrás da figura da subjetividade jurídica:

[...] O conceito de um sujeito de Direito como portador (suporte) do direito subjetivo (no sentido de titularidade jurídica - Berechtigung) é aqui, no fundo, apenas uma outra forma deste conceito de direito subjetivo que, no essencial, foi talhado pela noção de propriedade. ${ }^{11}$.

\footnotetext{
${ }^{10}$ COUTRIN, Gilberto. História \& reflexão Consolidação do Capitalismo e Brasil Império, p. 20.

11 KELSEN, Hans. Teoria Pura do Direito; ed. Martins Fontes; São Paulo; 1999. p. 119.
} 
Vale na pesquisa outro trecho da mesma obra de autoria de Hans Kelsen, onde fica bastante esclarecido a ideologia por detrás do valor liberdade que embasou este primeiro contexto que ficou aclamado como gerações (dimensões) de direitos:

Assim, escreve Puchta: O conceito fundamental do Direito é a liberdade [...] o conceito abstrato de liberdade é: possibilidade de alguém se determinar para algo... O homem é sujeito de Direito pelo fato de lhe competir aquela possibilidade de se determinar, pelo fato de ter uma vontade', quer dizer: pelo fato de ser livre. ${ }^{12}$.

Portanto, a vertente do positivismo jurídico reconhece propósitos bastante interessados e o aspecto ideológico na criação da abstração jurídica da figura do sujeito de direitos, bem como de seu respectivo embasamento no valor liberdade:

\begin{abstract}
Ainda que o indivíduo A sinta necessidade da mercadoria do indivíduo $B$, não se apodera pela força, nem vice e versa, mas reconhecem-se mutuamente como proprietários, como pessoas cuja vontade impregna suas mercadorias. Em decorrência, entra aqui de imediato o momento jurídico da pessoa e da liberdade, na medida em que está contida na primeira; Nenhum deles se apodera da propriedade do outro pela força. Cada um cede voluntariamente (...) Pelo próprio ato da troca, o indivíduo, cada um dos indivíduos está refletido em si mesmo o sujeito exclusivo e dominante (determinante) do ato da troca. Com isso, portanto, está posta a completa liberdade do indivíduo ${ }^{13}$.
\end{abstract}

Não se pode esquecer que a produção da época precisava de um contingente para o qual se destinasse, em suma, era preciso da formação de mercado que consumisse a produção e a ideia de reconhecer o elemento volitivo pelo viés da equiparação de todos à mesma titularidade era primordial não só para a designação da produção da época, bem como formação da mão de obra necessária nesta produção:

De fato, como a mercadoria ou o trabalho são determinados tão somente como valor de troca e a relação pela qual as diferentes mercadorias se relacionam entre si

\footnotetext{
12 PUCHTA apud KELSEN, 1999, p. 119.

${ }^{13}$ MARX, K. Grundrisse, São Paulo, Boitempo, 2011, p.187.
} 
(se apresenta) como troca desses valores de troca, como sua equiparação, os indivíduos, os sujeitos, entre eles os quais esse processo transcorre são determinados simplesmente como trocadores. Entre eles, não existe absolutamente nenhuma diferença, considerada a determinação formal (...). Cada um tem a mesma relação com o outro que o outro tem com ele. A sua relação como trocadores é, por isso, relação de igualdade. É impossível detectar qualquer diferença ou mesmo antagonismo entre eles, nem sequer dissim ilaridade ${ }^{14}$.

Portanto, a análise subjetiva pontuada na divergência assumida por Norberto Bobbio em detrimento a Karl Marx acerca de um dos mais significativos documentos inseridos na primeira geração (dimensão) de direitos deve ser renovada ou reinvocada na terceira geração (dimensão) de direitos.

\section{Projeção Subjetiva de Karl Marx aplicável na Terceira Geração (Dimensão) de Direitos}

Para esta primeira geração (dimensão) de direitos, há uma análise que se volta "a quem" se favoreceu com as respectivas proteções jurídicas (perspectiva subjetiva), em suma, para quem tais direitos abstratamente universais foram protegidos com o objetivo de serem efetivados.

Portanto, a universalidade não transcende ou supera o âmbito das previsões e textualizações jurídicas, de modo que, no plano da materialidade, tais direitos foram efetivos somente para alguns em detrimento dos demais.

Como seria esta mesma perspectiva (critério dos sujeitos e da efetividade) para a terceira geração (dimensão) de direitos?

Nos estudos da terceira geração (dimensão) de direitos, vale pontuar uma significativa peculiaridade que aparece no trâmite da pesquisa, em suma, a proteção de conteúdos que não referenciavam categorias específicas de sujeitos e que começaram a galgar juridicamente protegidas, ou seja, ao contrário de prerrogativas interessadas da classe que saiu vencedora naquele momento atinente a primeira geração (dimensão) de direitos; a terceira geração (dimensão) de direitos foi marcada pela proteção de conteúdos e prerrogativas

${ }^{14}$ MARX, K. Grundrisse, p. 184-185 
de titularidade indeterminada, dentre as quais, ar atmosférico, meio ambiente de modo geral, patrimônio histórico da humanidade e outros.

A peculiaridade da proteção de direitos e conteúdos que não referenciaram categorias específicas e sujeitos determinados, tais como, ar atmosférico, paz, recursos hídricos, patrimônio da humanidade tiveram sua origem na qualidade de uma resposta a um momento de degradação e de constantes atrocidades humanas, violências, destruição de patrimônios históricos e culturais, incluindo o ineditismo de utilização de armas nucleares como mácula radiativa no planeta.

Destaca-se, na Segunda Guerra Mundial, o Japão que sofreu uma escalada de violência que culminou com não só o pesadelo atômico e humanitário das cidades de Hiroshima e Nagasaki, mas também sofrimentos e violências em cidades como Osaka que foi particularmente atingida, sofrendo mais de 10 mil mortes de civis nos meses de março, junho, julho e agosto de 1945.

Ainda a violência sofrida pela cidade de Kassel, na região de Hesse, no centro-oeste da Alemanha, que foi alvo de uma campanha de bombardeio contínuo, que começou no início de 1942 e durou quase até o fim da Segunda Guerra Mundial, em 1945.

A cidade alemã de Darmstadt, no sudoeste do país, sofreu vários ataques aéreos, principalmente durante 1943 e 1944, atentando-se ao mais destrutivo registrado no ataque de 11 a 12 de setembro de 1944, quando a RAF realizou um bombardeio intenso sob a cidade.

Tóquio também foi uma cidade historicamente bastante bombardeada pelos americanos, inclusive os Estados Unidos já haviam executado um bombardeio menor na capital japonesa em abril de 1942, porém o bombardeio foram significativamente intensificados quase dois anos mais tarde, na maioria, marcado com poderosos B-29, colocando as suas capacidades para o uso extensivo sobre Tóquio, valendo lembrar que as missões sobre Tóquio, o ataque de 9 à 10 março de 1945, cujo codinome era Operação Capela, foi o mais significativo nesta cidade desde o início dos ataques.

As cidades de Berlim e Hamburgo experimentaram períodos contínuos de bombardeios durante a maior parte da guerra, registrando sangrentos e violentos bombardeios por uma força combinada de bombardeiros britânicos e americanos 
durante a última semana de julho de 1943, destacando a Operação Gomorra como a mais violenta.

Dresden, a sétima maior cidade da Alemanha na época da Segunda Guerra Mundial, e um centro industrial extremamente importante, viveu um dos bombardeios mais devastadores vistos até aquele ponto da história. Durante o período mais intenso, de 13 a 15 de fevereiro de 1945, 1.300 bombardeiros de uma força conjunta da Força Aérea Americana, despejaram mais de 3.900 toneladas de explosivos e bombas incendiárias sobre a cidade sitiada.

Durante a Segunda Guerra Mundial, Londres tornou-se um dos principais alvos do bombardeio alemão. Grandes áreas da cidade foram dizimadas e a natureza indiscriminada dos ataques destruiu muitos lugares sem valor estratégico como alvos - incluindo a Christchurch Greyfriars. Em 29 de dezembro de 1940, uma bomba incendiária atingiu o topo da igreja, rasgando o edifício e inflamando seu interior. $O$ inferno resultante fez com que o teto abobadado entrasse em colapso, destruindo o prédio e seu conteúdo.

Projetada pelo renomado arquiteto britânico Edward Barry e concluída em 1866 após quatro anos de construção, a Royal Opera House ficava, imponente, na esquina da Strada Reale, na histórica cidade de Valletta, porém a Royal Opera House se tornou uma vítima inocente da Luftwaffe alemã e em um ataque aéreo em 7 de abril de 1942 deixou o magnífico edifício em ruínas.

Durante a Segunda Guerra Mundial vários médicos alemães realizaram "experiências" desumanas, cruéis, e muitas vezes mortais em milhares de prisioneiros dos campos de concentração, incluindo as realizadas durante 0 Terceiro Reich, algumas classificadas com a finalidade de facilitar a sobrevivência dos militares do Eixo, realizando experimentos sobre reações à alta altitude, usando câmaras de baixa pressurização, para determinar a altitude máxima da qual as equipes de aeronaves danificadas poderiam saltar de paraquedas, em segurança; ou ainda experimentos de congelamento, utilizando os prisioneiros como cobaias para descobrir um método eficaz de tratamento para a hipotermia.

Outros experimentos como testes de medicamentos, bem como métodos de tratamento para ferimentos e enfermidades que os militares e a equipe de ocupação alemã encontravam nos campos de concentração de Sachsenhausen, Dachau, Natzweiler, Buchenwald e Neuengamme, os cientistas testaram 
agentes imunizantes e soros para prevenir e tratar doenças contagiosas como a malária, o tifo, a tuberculose, a febre tifoide, a febre amarela e a hepatite infecciosa, inoculando os prisioneiros com tais doenças; também registros de experimentos no campo de Ravensbrueck com enxertos ósseos, e onde foi testado o medicamento denominado sulfa (sulfanilamida) através das vidas dos prisioneiros; e, também, em Natzweiler e Sachsenhausen, os prisioneiros foram sujeitos aos perigosos gases fosgênio e mostarda, com o objetivo de testar possíveis antídotos.

Não se pode deixar de lembrar experimentos que buscaram aprofundar nos princípios raciais e ideológicos da visão nazista, incluindo o nome do médico Josef Mengele, em Auschwitz, que utilizou gêmeos, crianças e adultos, de forma desumana, e que também coordenou experiências sorológicas em ciganos, tal como fez Werner Fischer, em Sachsenhausen, para determinar como as diferentes "raças" resistiam às diversas doenças contagiosas.

Assim, foi uma resposta a este resultado de guerras, crises humanitárias que a percebe-se uma mudança quando se observa as prerrogativas e conteúdos que começaram a ser previstos e juridicamente positivados após tais atrocidades que assolaram a humanidade um pouco antes da metade do século $\mathrm{XX}$.

Direitos como meio ambiente, paz, patrimônio histórico e cultural da humanidade e outros tantos que não referenciavam categorias específicas de sujeitos começaram a galgar a esfera de proteção jurídica, incluindo a nomenclatura que a doutrina jurídica intitulou como difusos, justamente, fazendo referência a este aspecto de, dentro da perspectiva subjetiva, serem conteúdos de titularidade indeterminado, em suma, sem especificarem efetivamente sujeitos determinados.

Porém, vale concluir que analisar conteúdos subjetivamente indeterminados é insuficiente, pois a perspectiva de Karl Marx inclui a esfera da real efetividade e, desse modo, há certa problematização na efetividade de conteúdos difusos caracterizados por não referenciarem categorias específicas, uma vez que a proteção jurídica de direitos de titularidade indeterminada não possui uma categoria específica para serem representados ou ainda demandados na busca da respectiva materialização. 
No plano da efetividade de direitos que referenciam todos de um modo geral acabam não tendo quem os representem ou busque a respectiva efetivação, de modo que a especificação do sujeito, por exemplo, uma categoria ou um grupo de pessoas com interesses em comum gera legitimidade para, por exemplo, serem representados em juízo ou buscarem sua efetividade com uma hipotética execução.

A ideia de proteger o meio ambiente, ar atmosférico, patrimônio histórico e cultural e outros conteúdos que não referenciam categorias específicas acabam gerando falta e ausências em quem deve defender tais direitos, pois se tratando de um bem de todos indistintamente, o indivíduo em particular acaba sempre delegando para o outro o tempo, eventuais onerações e dispêndios em defender um interesse que não é somente dele (delegante), trata-se de um fenômeno bastante reconhecido na doutrina dos direitos difusos e coletivos denominado: Free riding.

O fenômeno Free Rinding designa, sobretudo, uma tendência natural decorrente dessas prerrogativas que, por não haver um titular específico, ninguém acaba tendo interesse em defendê-lo, sendo, inclusive, por isso que na tutela coletiva se exige a institucionalização de um órgão representante:

Isto acaba por justificar a construção de um modelo de processo coletiva em que o sistema eleja representantes da coletividade para atuar em favor dos titulares indeterminados dos direitos ou interesses, neutralizando ou, ao menos, mitigando esta tendência natural à imobilização deles por conta de efeito carona da atuação alheia (free riding). Há, portanto, um impulso natural à imobilização dos agentes na defesa dos bens $\operatorname{coletivos}^{15}$.

A expressão terminológica free rinding tem um significado próximo a "efeito carona", pois deflagra que em bens e direitos, tais como, paz, meio ambiente e outros que pertencem à terceira geração (dimensão), onde não há titulares determinados e todos acabam sendo responsáveis pela conservação, de forma que todos possuem a mesma responsabilidade sobre tais bens e o que é de todos acaba não sendo de nenhum, pois um acaba sempre transferindo a responsabilidade para o outro, sendo muito comum a imobilização e neutralidade

${ }^{15}$ GARJADONI, Fernando. F. Direitos Difusos e Coletivos I; vol. 34. Ed Saraiva; São Paulo. 2012, p. 17. 
de todos. Por isso é que é preciso de um órgão que represente a sua defesa desses direitos.

As ciências jurídicas tiveram que repensar a tutela de direitos sem uma titularidade específica e para isso teve que se repensar "quem" iria representar, em juízo, direitos sem titulares específicos “(...) Primeiro, a representação em juízo de interesses supraindividuais é fundamental para a tutela de direitos cuja titularidade é indeterminada"16.

As propostas de positivações respaldadas pela titularidade dos conteúdos era, de fato, um risco quando a máquina estatal instrumentalizava esta sujeição e, por isso, a ideia de previsão de conteúdos difusos e prerrogativas que não possuíam titulares determinados, tal como, meio ambiente, paz, enfim, gerando o momento que os constitucionalistas chamaram de terceira geração (dimensão) de direitos.

Do mesmo modo, houve uma extensão da positivação de bens e conteúdos com titulares indeterminados e difusos como forma de proteger o retrocesso totalitário que sucumbiu com a inserção da máquina estatal produzindo sujeição.

Portanto, a perspectiva subjetiva (titularidade e reais destinatários) examinada na terceira geração (dimensão) de direitos acaba observando a proteção de conteúdos e prerrogativas que não referenciaram sujeitos específicos, mas sujeitos indeterminados e no plano da efetividade, percebe-se a necessidade estatal de legitimar e institucionalizar órgãos específicos que pudessem defender, representar e efetivar esses direitos, daí a relevância do Ministério Público como um bem conhecido legitimado na defesa de direitos compreendidos como difusos.

\section{CONSIDERAÇÕES FINAIS}

O presente trabalho retoma o ponto de análise da divergência de autoria de Karl Marx no trabalho intitulado "Sobre a Questão Judaica" resistida e em contraposição ao jurista Norberto Bobbio quando reinvoca o aspecto da universalidade desses direitos, afastando, assim, questionamentos subjetivos

${ }^{16}$ GARJADONI, Fernando. F. Direitos Difusos e Coletivos I, p. 17 
acerca de favorecidos e beneficiados no decorrer das diferentes gerações ou dimensões de direitos.

Ocorre que a reafirmação da universalidade como característica dos direitos fundamentais não considera o significativo grau de abstração, pois, em que pese teorizados universalmente tendo em vista que esses conteúdos são direitos da pessoa humana (esfera do dever ser), tal universalidade não transcende a dimensão abstrata daquilo que está positivado, senão tão somente para alguns que tiveram seus interesses satisfeitos aproveitando o favoritismo político do contexto histórico em que ocorreram as respectivas proteções jurídicas no decorrer das diferentes dimensões de direitos.

Quando Karl Marx afirma que a declaração não referenciou o homem universal, mas o burguês, priorizando quem, de fato, viu seus direitos sendo efetivados, na verdade ele faz uma análise subjetiva que não foi aproveitada para as demais gerações (dimensões) de direitos, faltando uma perspectiva de crise das gerações (dimensões) de direitos na perspectiva dos sujeitos favorecidos e no campo da efetividade.

Nesse sentido, retomar esta análise subjetiva de Karl Marx para um dos documentos pertencentes à primeira geração (dimensão) de direitos, aplicando e estendendo para a terceira dimensão de direitos passa ser o propósito da investigativa que declina por descobertas bastante peculiares.

Um dos conteúdos que foram atribuídos à terceira dimensão, consiste, justamente, na determinação do que ficou conhecido como direitos difusos como sendo prerrogativas que não referenciaram categorias subjetivas determinadas, tal como ocorreu no período em Marx observou a materialização em favor da classe burguesa que marcou a primeira geração de orientação precipuamente liberal.

$\mathrm{Na}$ verdade, a terceira geração ou dimensão de direitos foi marcada por uma orientação protetiva com certo grau de ineditismo que começou a positivar conteúdos que não referenciavam sujeitos determinados, por isso foram denominados direitos difusos e as razões desta mudança estão baseadas, justamente, em uma resposta ou uma tentativa de proteger patrimônios da humanidade que foram destruídos com as guerras, preocupação com o meio ambiente, ar atmosférico e com a radiação, flora e a fauna, até, indagações acerca da paz, em suma, começou um processo de concessão na positivação 
de conteúdos que, de fato, não beneficiassem somente categorias, mas referenciassem a todos como uma forma não só de compensação, mas responder a violência, aos sangrentos episódios históricos, tais como o Holocausto e utilização de armamentos nucleares com preocupantes prejuízos não só humanos, mas também ambientais.

Explicando, inclusive, a temática da investigação que faz menção temporal à terceira dimensão de direitos como um momento posterior a uma geração de guerras, mortes, utilização de armamentos nucleares, enfim, uma verdadeira crise humanitária marcada por graus extremos de atrocidades e que o título do trabalho fez referência como uma geração de direitos desumanos.

Ocorre que a perspectiva subjetiva desta dimensão ou geração de direitos que tentou responder as sangrentas crises que assolaram a humanidade até a metade do século $X X$, possui um significativo grau de problematização quando se alinham na positivação de conteúdos difusos que não referenciam categorias específicas, haja vista que não referenciando certas categorias, não há representatividade das mesmas na concretização, materialização ou defesa em juízo.

$\mathrm{Na}$ verdade a representatividade, em tese, seria de todos, porém ocorre que quando um bem e de propriedade de todos, os titulares sempre delegam ao outro a responsabilidade que possuem, de modo que há significativa recorrência em uma inércia de todos que a doutrina e estudiosos da tutela coletiva chamaram de fenômeno free rinding (efeito carona).

A crise da tradicional proposta teórica de Karel Vasak acerca das gerações ou dimensões de direitos, portanto, possuem duas esferas críticas: primeiramente quanto ao critério do conteúdo e, em segundo lugar, quanto ao critério dos sujeitos. E, ainda, quanto a esses dois critérios, afirma-se uma crise da acepção das gerações ou dimensões de direitos pela utilização da ordem cronológica de previsão de prerrogativas, uma vez que a proposta teórica determina um primeiro momento de previsão fundado nos direitos civis e políticos, uma segunda fase de proteção se tratando de direitos sociais e econômicos e, por fim, um terceiro contexto de previsão falando de direitos atinentes à fraternidade.

Ocorre que quanto ao critério do conteúdo ou dos direitos, tais momentos de seu surgimento não podem ser considerados, uma vez que a 
cronologia ou ordem sequencial de suas proteções não possuem aptidão para determinarem tais direitos, pois direitos fundamentais surgem de inúmeras fontes e influências, dentre as quais, de natureza psicológica, sociológica, histórica, antropológica e tecnológica, de modo que a cronologia sequencial de previsões é somente uma dos fatores que influenciam no surgimento desses direitos e não o único a ser considerado.

Quanto ao critério dos sujeitos que o trabalho buscou trabalhar a partir da celeuma entre Bobbio na obra denominado "A Era dos Direitos" e Marx no seu trabalho intitulado "Sobre a Questão Judaica" na afirmação de que a declaração não fazia referencia ao homem universal, mas ao homem burguês, tratando-se, justamente, de uma perspectiva subjetiva que adentrava no campo da real materialidade para concluir que as proteções foram ocorrendo para serem efetivas a determinadas categorias de sujeitos na medida em que eram favorecidas em um dado momento histórico e político que levaram a galgar tais previsões para terem efetivados seus respectivos interesses.

Portanto, quando o trabalho se propõe a estender a perspectiva subjetiva para a terceira geração ou dimensão de direitos, a proposta encontra a tentativa de responder a atrocidades com a proteção de conteúdos caracterizados por não referenciarem sujeitos especificados, mas direitos de titularidade indeterminada, como recursos hídricos, patrimônio da humanidade, meio ambiente, enfim, direitos de todos sem categorias que pudessem buscar sua materialização e os e a respectiva representatividade em juízo.

Por isso, o fenômeno free rinding reiterado principalmente pela doutrina da tutela coletiva está intrinsicamente atrelada a esta perspectiva subjetiva quando a investigativa se propõe a aplicá-la na terceira geração ou dimensão de direitos, pois este contexto foi marcado por um momento de proteção de conteúdos difusos que exigiu não só a desestruturação dos regimes totalitários, mas também a estruturação de legitimados estatais que pudessem materializar ou demandar em juízo por direitos que somente a previsão não seria suficiente para efetivar a tutela jurídica, sendo o ponto de relevância deste trabalho no propósito de desenvolver uma perspectiva subjetiva para a proposta de Karel Vasak acerca das gerações ou dimensões de direitos.

\section{REFERÊNCIAS DAS FONTES CITADAS}


AGAMBEN, Giorgio. Estado de Exceção. Tradução Iraci D. Poleti. São Paulo: BoiTempo, 2004. Coleção Estado de Sítio.

BOBBIO, Norberto. A Era dos Direitos. Tradução de Carlos Nelson Coutinho. Rio de Janeiro: Elsevier, 2004.

BOBBIO, Norberto. A Era dos Direitos. Tradução de Carlos Nelson Coutinho. Rio de Janeiro: Elsevier, 1992.

BONAVIDES, Paulo. Curso de direito constitucional. 7. ed. São Paulo: Malheiros, 1998.

BITTAR, Eduardo C. B. Democracia, justiça e direitos humanos: estudos de teoria crítica e filosofia do direito. São Paulo: Saraiva, 2011.

COUTRIN, Gilberto. História \& reflexão Consolidação do Capitalismo e Brasil Império; vol. 3. 8ª edição. São Paulo: Saraiva, 1999.

EDELMAN, Bernard. O direito captado pela fotografia: elementos para uma teoria marxista do direito. Tradução Soveral Martins e Pires de Carvalho. Coimbra: Centelha, 1976.

Pensée, 1973.

Le sujet du droit chez Hegel. Tradução Celso Naoto Kashiura Jr. La

FOCAULT, Michel. Saber y verdade. Tradução de Julia Varela e Fernando Alvarez-Uria. Madrid: Las Ediciones de la piqueta, 1991.

FONSECA, Ricardo Marcelo. Modernidade e contrato de trabalho: do sujeito de direito à sujeição jurídica. São Paulo: LTr, 2002.

Para uma possível teoria da história dos direitos humanos. v. 16, n. 1 Fortaleza: Pensar, jan./jun. 2011.

GARJADONI, Fernando da Fonseca. Direitos Difusos e Coletivos. vol. 34. Ed Saraiva; São Paulo. 2012.

GORENDER, Jacob; Os Economistas - O Capital de Karl Marx: Crítica Da economia Política. São Paulo: Nova Cultural Ltda, 1996.

GIACÓIA JR, Oswaldo. Heinderger urgente: Introdução a um novo pensar, São Paulo: Três Estrelas, 2013.

KASHIURA JR, Celso Naoto. Sujeito de direito e o capitalismo. 2012. 177 f. Tese (Doutorado em Filosofia e Teoria Geral do Direito)-Faculdade de Direito da Univesidade de São Paulo, São Paulo, 2012.

KELSEN, Hans. Teoria Pura do Direito. Tradução João Baptista Machado. São Paulo: Martins Fontes, 1999.

KEYNES, John Maynard; Teoria Geral do Emprego, do Juro e da Moeda, Tradução CRUZ, Mario Ribeiro DA. São Paulo: Editora Atlas, 1992. 
LIPIETZ, Alain. Audácia: uma alternativa para o século XXI. São Paulo: Ed. Nobel. 1991.

MAZZUOLLI, Valério de Oliveira. Curso de direito internacional público. 7. ed. São Paulo: Revistas dos Tribunais, 2013.

MARX, Karl. O capital. Tradução de Regis Barbosa e Flávio Kothe. São Paulo: Abril Cultural, 1983.

. Grundrisse. Tradução Mario Duayer et al., São Paulo, Boitempo, 2011.

A questão judaica. 2. ed. São Paulo: Moraes, 1991.

MORAES, Alexandre de. Direito constitucional. 19. ed. São Paulo: Atlas, 2006.

NOVELINO, Marcelo. Manual de direito constitucional. 8. ed. São Paulo: Método, 2013.

PACHUKANIS, Evgeni B. A Teoria geral do direito e a construção do socialismo. Tradução de Paulo Bessa. Rio de janeiro: Renovar, 1989.

SAVIGNY, Friedrich Carl. Traité de Droit Romain. Trad. M. Ch. Guenoux. T I Paris: Libraire de Firmin Didot Freres, 1855

SCHÄFER, Jairo. Classificação dos direitos fundamentais: do sistema geracional ao sistema unitário: uma proposta de compreensão. Porto Alegre: Livraria do Advogado, 2005.

SILVA, José Afonso. Curso de direito constitucional positivo. 26. ed. São Paulo: Malheiros, 2006.

WEIS, Carlos. Direitos humanos contemporâneo. 2. ed. São Paulo: Malheiros, 2010. 